University of Wollongong

Research Online

Faculty of Engineering and Information

Faculty of Engineering and Information

Sciences - Papers: Part A

Sciences

$1-1-2016$

Dynamic response of symmetrical and asymmetrical sandwich plates with shear thickening fluid core subjected to penetration loading

Z. H. Tan

Wuhan University of Technology

L Zuo

Wuhan University of Technology

Weihua Li

University of Wollongong, weihuali@uow.edu.au

L S. Liu

Wuhan University of Technology

Peng Zhai

University of Wollongong, pz449@uowmail.edu.au

Follow this and additional works at: https://ro.uow.edu.au/eispapers

Part of the Engineering Commons, and the Science and Technology Studies Commons

Research Online is the open access institutional repository for the University of Wollongong. For further information contact the UOW Library: research-pubs@uow.edu.au 


\title{
Dynamic response of symmetrical and asymmetrical sandwich plates with shear thickening fluid core subjected to penetration loading
}

\begin{abstract}
Symmetrical and asymmetrical sandwich plates with a shear thickening fluid (STF) core were designed to be penetrated by a cylindrical projectile at various impact velocities. These STFs consist of SiO2/PEG400, and the volume fractions of $\mathrm{SiO} 2$ nano-particles are $54 \%$ and $56 \%$, respectively. Failure mode of the rear face sheet of the symmetrical sandwich plate is petal perforation, but the rear face sheet of the asymmetrical sandwich plate failed in plug perforation mode at the velocity of less than $80 \mathrm{~m} / \mathrm{s}$ and in the petal perforation mode at the velocity faster than $90 \mathrm{~m} / \mathrm{s}$. The results showed that both the face sheet and the STF core played different roles in impact resisting properties and energy absorption of the sandwich plate at different impact velocities. The thickness of the rear sheet has a significant influence on the energy absorption at low impact velocity, while this influence can be ignored at high impact velocity. The effects of the particle volume fraction, impact velocity and thickness of rear face sheet on the deformation mechanism and energy absorption of the sandwich plate were also discussed.

\section{Disciplines}

Engineering | Science and Technology Studies

\section{Publication Details}

Tan, Z. H., Zuo, L., Li, W. H., Liu, L. S. \& Zhai, P. C. (2016). Dynamic response of symmetrical and asymmetrical sandwich plates with shear thickening fluid core subjected to penetration loading. Materials and Design, 94 105-110.
\end{abstract}




\section{Title Page}

Title: Dynamic response of symmetrical and asymmetrical sandwich plates with shear thickening fluid core subjected to penetration loading

Authors: Z.H. Tan ${ }^{1, *}$, L. Zuo ${ }^{1}$, W.H. Li ${ }^{2}$, L.S. Liu ${ }^{1}$, P.C. Zhai ${ }^{1}$

1. Department of Engineering Structure and Mechanics, School of Science, Wuhan University of Technology, Hubei, 430070, P.R. China.

2. School of Mechanical, Materials and Mechatronic Engineering, University of Wollongong, Wollongong, NSW 2522, Australia.

*Corresponding Author. Email: zhtan@whut.edu.cn Tel./Fax: 00862787108026

Z.H. Tan Email: zhtan@whut.edu.cn

L.Zuo_Email: zuolelive@163.com

W.H. Li Email: weihuali@uow.edu.au

L.S. Liu_Email: liulish@whut.edu.cn

P.C.Zhai Email: pczhai@whut.edu.cn 


\title{
Dynamic response of symmetrical and asymmetrical sandwich plates
}

\section{with shear thickening fluid core subjected to penetration loading}

\author{
Z.H. Tan ${ }^{1, *}$, L. Zuo ${ }^{1}$, W.H. Li ${ }^{2}$, L.S. Liu ${ }^{1}$, P.C. Zhai ${ }^{1}$ \\ ${ }^{1}$ Department of Engineering Structure and Mechanics, School of Science, Wuhan University of \\ Technology, Hubei, 430070, P.R. China. \\ ${ }^{2}$ School of Mechanical, Materials and Mechatronic Engineering, University of Wollongong, \\ Wollongong, NSW 2522, Australia.
}

Abstract: Symmetrical and asymmetrical sandwich plates with a shear thickening fluid (STF) core were designed to be penetrated by a cylindrical projectile at various impact velocities. These STFs consist of $\mathrm{SiO}_{2} / \mathrm{PEG} 400$, and the volume fractions of $\mathrm{SiO}_{2}$ nano-particles are $54 \%$ and $56 \%$, respectively. Failure mode of the rear face sheet of the symmetrical sandwich plate is petal perforation, but the rear face sheet of the asymmetrical sandwich plate failed in plug perforation mode at the velocity of less than $80 \mathrm{~m} / \mathrm{s}$ and in the petal perforation mode at the velocity faster than $90 \mathrm{~m} / \mathrm{s}$. The results showed both the face sheet and the STF core played different roles in impact resisting properties and energy absorption of the sandwich plate at different impact velocities. The thickness of the rear sheet has a significant influence on the energy absorption at low impact velocity, while this influence can be ignored at high impact velocity. The effects of the particle volume fraction, impact velocity and thickness of rear face sheet on the deformation mechanism and energy absorption of the sandwich plate were also discussed.

Keywords: shear thickening fluid (STF), sandwich plate, penetration, failure mode, energy absorption.

*Corresponding Author. E-mail: zhtan@ whut.edu.cn. Tel./Fax: 00862787108026 


\section{Introduction}

A sandwich structure has been widely used as the energy absorption component in protection system against the penetration of the projectile. The core of the sandwich structure consists of metal foam, fiber, and other soft materials [1-4], and it has low specific mass, high specific stiffness and high energy absorption that can improve the impact resistance and energy absorption of sandwich structure. It is a challenge for researchers and engineers to find new materials with properties needed for the core of sandwich structures.

Shear thickening fluid (STF) consists of a stabilized dispersion of hard nano-particles in a carrier solvent, and its viscosity can increase immediately, even into solid-like state when subjected to impact loading, and then recover after the impact loading is removed. Due to their special properties, STF can be used as an energy absorber and vibration controller, etc [5-6].

Over the past several decades a lot of research has been conducted on the mechanical properties and applications of STF [7-11]; for example, Jiang et al. [9] studied the propagation and attenuation of the stress wave in STF by using SHPB, and Lim et al. [10] evaluated the critical condition of STF transition from fluid to solid-like behaviour at different strain rates, Petel et al. [11] investigated the influence that particle strength had on the ballistic performance of STF and found that suspensions with $61 \% \mathrm{SiO}_{2}$ and $\mathrm{SiC}$ exhibited the greatest projectile deceleration performance. Further work on STF was to improve the ballistic performance of fabric impregnated by STF at different load cases [12-19]. Feng et al. [18] illustrated the 
stab resistant properties of fabrics impregnated with STF with sub-micrometer silica and fumed silica particles on quasi-static loading. Park et al. [19] studied the energy absorption characteristics of Kevlar fabric impregnated by STF at the velocity between 1 to $2 \mathrm{~km} / \mathrm{s}$ by experimental and numerical methods. However, very few researches are available to study dynamic performance of the sandwich structure incorporating STF its core [20]. This is the major motivation of this research.

In this work, STF was used as the core of sandwich plate subjected to penetration by a cylindrical projectile at the velocity ranging from around $30 \mathrm{~m} / \mathrm{s}$ to $120 \mathrm{~m} / \mathrm{s}$. STF with $54 \%$ and $56 \%$ volume fraction was fabricated and used as the core of sandwich plates. To analyze the role played by STF in the impact resisting properties and energy absorption of sandwich plate, two kinds of rear face sheets with different thickness were designed and tested. The failure mechanism and energy absorption of the sandwich plates were also discussed.

\section{Experimental procedures}

\subsection{Materials and Specimens}

In this paper the $\mathrm{STF}$ consists of $\mathrm{SiO}_{2}$ nano-particles and polyethylene glycol of molecular weight 400 (PEG400). The $\mathrm{SiO}_{2}$ sphere was fabricated by Stober methods [21-22], and the diameter is about $300 \mathrm{~nm}$ in diameter tested using S-4800 field emission scanning electron microscope (FE-SEM), as shown in Fig. 1. According to the $\mathrm{SiO}_{2}$ volume fraction of $54 \%$ and $56 \%$, the specific $\mathrm{SiO}_{2}$ nano-particles and PEG400 mixture solvent was treated in a planetary ball mill for 2-3 hours. And variation of the viscosity vs. shear strain rate of STF was tested by a rheometer 
(Anton-Paar MCR301) in University of Science and Technology of China.

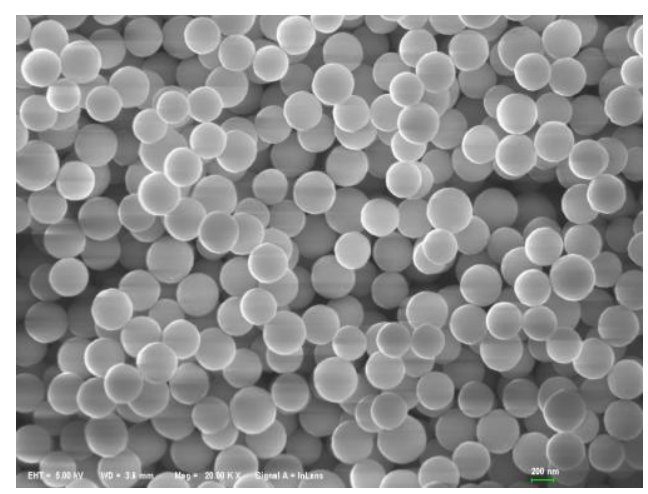

Fig. 1 The SEM graph of the $\mathrm{SiO}_{2}$ particle.

The sandwich plate consists of front and rear face sheets with the edges sealed by PMMA. Both front face sheet and rear face sheet are the pure aluminium. And the Young's modulus is about $71 \mathrm{GPa}$, the strength is about $232 \mathrm{MPa}$ [23]. Two types of sandwich plates were designed in this paper: (1) the front and rear sheets are both 0.2 mm thick (marked by ' $S$ ' which means symmetry), (2) the front face sheet is $0.2 \mathrm{~mm}$ thick and the rear face sheet is $0.5 \mathrm{~mm}$ thick (marked by ' $\mathrm{A}$ ', means asymmetry), as shown in the Table 1.

\subsection{Experimental apparatus}

The steel cylindrical projectile is $\Phi 6 \mathrm{~mm} \times 20 \mathrm{~mm}$ and weighs $4.2 \mathrm{~g}$; it was fired by a light gas gun. Two laser velocimeters were used to measure the impact velocity and residual velocity of the projectile. The specimen was placed between these two laser velocimeters. The impact velocity varies from $30 \mathrm{~m} / \mathrm{s}$ to $120 \mathrm{~m} / \mathrm{s}$. The schematic diagram of the light gas gun is shown in Fig. 2. 


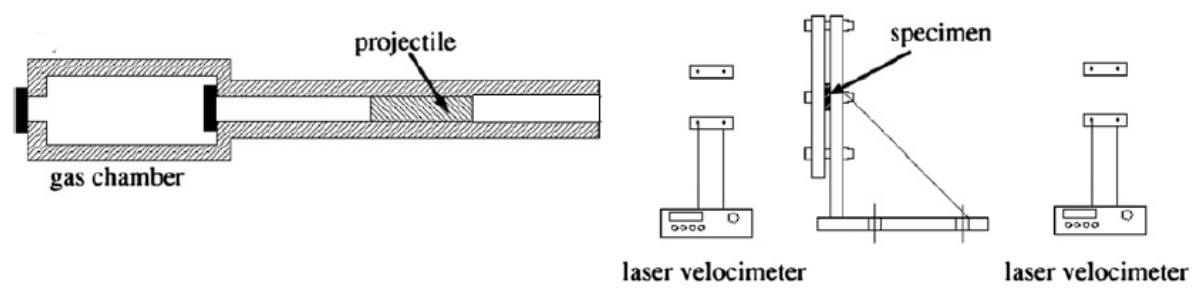

Fig. 2 Schematic diagram of the experimental configuration.

\section{Results and discussion}

\subsection{Viscosity of the STF at different shear strain rate}

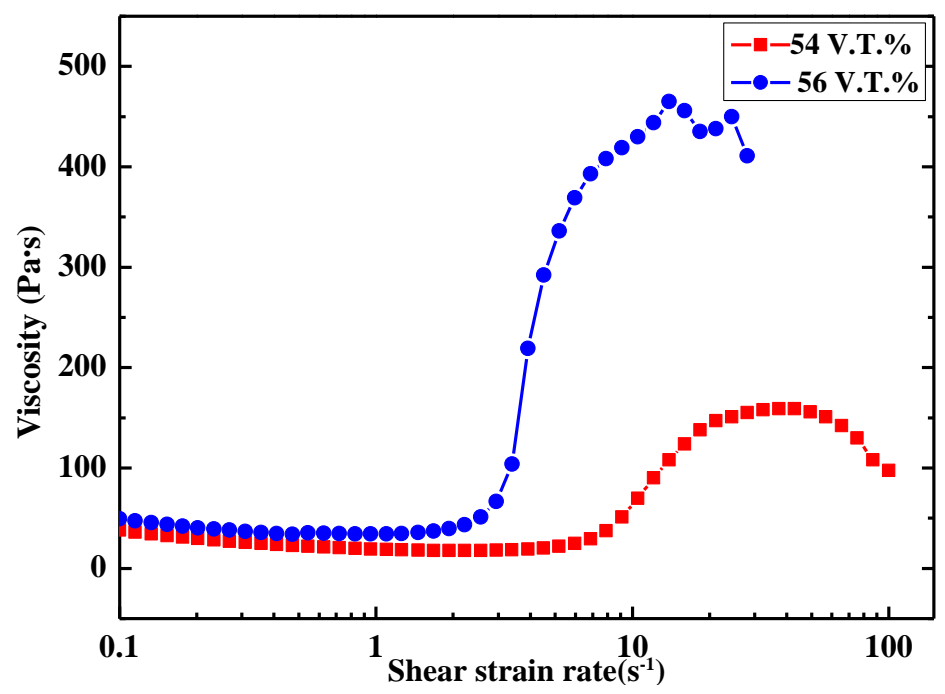

Fig. 3 The curves of viscosity vs. shear strain rates of 54\% and 56\% STFs.

The curves of viscosity vs. shear strain rate of STFs in this paper were tested and shown in Fig. 3. The viscosity of both STFs is about $50 \mathrm{~Pa} \cdot \mathrm{s}$ at low strain rate, and the maximum viscosity of $54 \%$ and $56 \%$ STFs is about 150 and $500 \mathrm{~Pa} \cdot \mathrm{s}$ at high shear strain rate, respectively. And it is obvious that the viscosity of $56 \%$ STFs is greater than the $54 \%$ STFs at high shear strain rates, while the critical shear strain rate of shear thickening of $56 \%$ STFs is less than the $54 \%$ STFs in Fig. 3.

\subsection{Failure modes of the different types of structures}

\subsubsection{Case 1: symmetrical structure case}

For the symmetrical structure, the front and rear face sheets are both $0.2 \mathrm{~mm}$ 
thick. The failure modes of the symmetrical sandwich plates with 54\% and 56\% STF cores were nearly the same as shown in Fig. 4. It can be seen from Table 1 and Fig. 4 that the failure mode of the front face sheet was plug, while the rear face sheet failed in torn petal modes at different impact velocities, as shown in Fig. 4(b). The face sheets of the symmetrical sandwich plate without an STF core failed in the plug mode.

Table 1 The experimental results

\begin{tabular}{|c|c|c|c|c|c|}
\hline $\begin{array}{l}\text { Specimen } \\
\text { No. }\end{array}$ & $\begin{array}{l}\text { Thickness of face } \\
\text { sheet/STF } \\
\text { core/rear sheet } \\
(\mathrm{mm})\end{array}$ & $\begin{array}{l}\text { Impact } \\
\text { velocity } \\
(\mathrm{m} / \mathrm{s})\end{array}$ & $\begin{array}{l}\text { Residual } \\
\text { velocity } \\
(\mathrm{m} / \mathrm{s})\end{array}$ & $\begin{array}{c}\text { Energy } \\
\text { absorption } \\
\text { (J) }\end{array}$ & Failure mode \\
\hline S-0-1 & $0.2 / 0 / 0.2$ & 71.63 & 67.52 & 1.20 & Perforation, Plug failure mode \\
\hline S-0-2 & $0.2 / 0 / 0.2$ & 93.41 & 91.82 & 0.62 & Perforation, Plug failure mode \\
\hline $\mathrm{S}-0-3$ & $0.2 / 0 / 0.2$ & 115.62 & 114.53 & 0.52 & Perforation, Plug failure mode in Fig.4(a) \\
\hline$A-0-1$ & $0.2 / 0 / 0.5$ & 71.31 & 50.03 & 5.4 & Perforation, Plug failure mode \\
\hline$A-0-2$ & $0.2 / 0 / 0.5$ & 96.42 & 93.51 & 1.16 & Perforation, Plug failure mode \\
\hline A-0-3 & $0.2 / 0 / 0.5$ & 110.74 & 108.63 & 0.97 & Perforation, Plug failure mode \\
\hline S-54-1 & $0.2 / 20 / 0.2$ & 32.65 & 0 & 2.24 & Perforation, petal failure mode \\
\hline S-54-2 & $0.2 / 20 / 0.2$ & 61.07 & 36.81 & 4.99 & Perforation, petal failure mode in Fig. 4(b) \\
\hline S-54-3 & $0.2 / 20 / 0.2$ & 93.32 & 72.72 & 7.18 & Perforation, petal failure mode \\
\hline S-54-4 & $0.2 / 20 / 0.2$ & 116.96 & 97.80 & 8.64 & Perforation, petal failure mode \\
\hline A-54-1 & $0.2 / 20 / 0.5$ & 65.1 & 0 & 8.87 & Plug, dish and bulge \\
\hline A-54-2 & $0.2 / 20 / 0.5$ & 70.67 & 35.53 & 7.84 & Plug, dish and bulge in Fig. 5(a) \\
\hline A-54-3 & $0.2 / 20 / 0.5$ & 93.44 & 68.91 & 8.36 & Perforation, petal failure mode in Fig. 5(b) \\
\hline A-54-4 & $0.2 / 20 / 0.5$ & 113.83 & 91.48 & 9.63 & Perforation, petal failure mode in Fig. 5(c) \\
\hline S-56-1 & $0.2 / 20 / 0.2$ & 44.25 & 0 & 4.11 & Perforation, petal failure mode \\
\hline S-56-2 & $0.2 / 20 / 0.2$ & 63.1 & 31.92 & 6.22 & Perforation, petal failure mode \\
\hline S-56-3 & $0.2 / 20 / 0.2$ & 91.53 & 66.20 & 8.39 & Perforation, petal failure mode \\
\hline S-56-4 & $0.2 / 20 / 0.2$ & 105.8 & 77.03 & 10.88 & Perforation, petal failure mode in Fig. 4(c) \\
\hline A-56-1 & $0.2 / 20 / 0.5$ & 72.46 & 0 & 11.02 & Plug, dish and bulge \\
\hline A-56-2 & $0.2 / 20 / 0.5$ & 80.1 & 20.20 & 12.61 & Plug, dish and bulge in Fig. 5(d) \\
\hline A-56-3 & $0.2 / 20 / 0.5$ & 93.15 & 50.88 & 12.78 & Perforation, petal failure mode in Fig. 5(e) \\
\hline A-56-4 & $0.2 / 20 / 0.5$ & 105.8 & 71.02 & 12.92 & Perforation, petal failure mode in Fig. 5(f) \\
\hline
\end{tabular}

* The plates consist of three parts; the letters 'A' or 'S' in the first part mean symmetry or asymmetry, the second part is the thickness of the core, and the last part is the experiment number. 

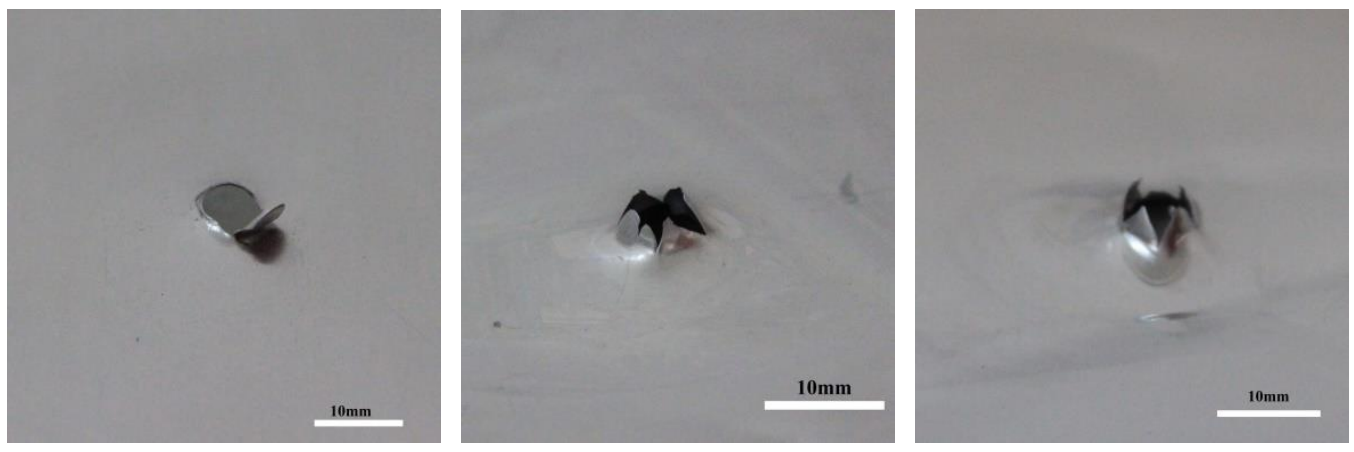

Fig. 4 Typical failure modes of symmetrical sandwich plate: (a) without STF core at $115.6 \mathrm{~m} / \mathrm{s}(\mathrm{S}-0-2)$, (b) with $54 \%$ STFs at $61.07 \mathrm{~m} / \mathrm{s}(\mathrm{S}-54-2)$ and (c) with $56 \%$ STFs at $105.8 \mathrm{~m} / \mathrm{s}(\mathrm{S}-56-4)$.

\subsubsection{Case 2: asymmetrical structure case}

For the case of asymmetrical sandwich plate, the front and rear sheets were 0.2 and $0.5 \mathrm{~mm}$ thick, respectively. The typical failure modes of the rare face sheets are shown in Fig. 5. It can be seen from this figure that the failure mode of the rear sheet of asymmetry case is different from that of symmetry case in Fig. 4. The rear sheet of the asymmetrical case failed in plug mode, unlike that of the symmetrical case. The front face sheet of the asymmetrical sandwich plate still failed in plug mode, while the rear sheet failed in a bulge and dish deformation at low velocity, but when the impact velocity increased, failure mode turned to petal shaped perforation. This is different from that in Fig. 4 at the corresponding impact velocity. 

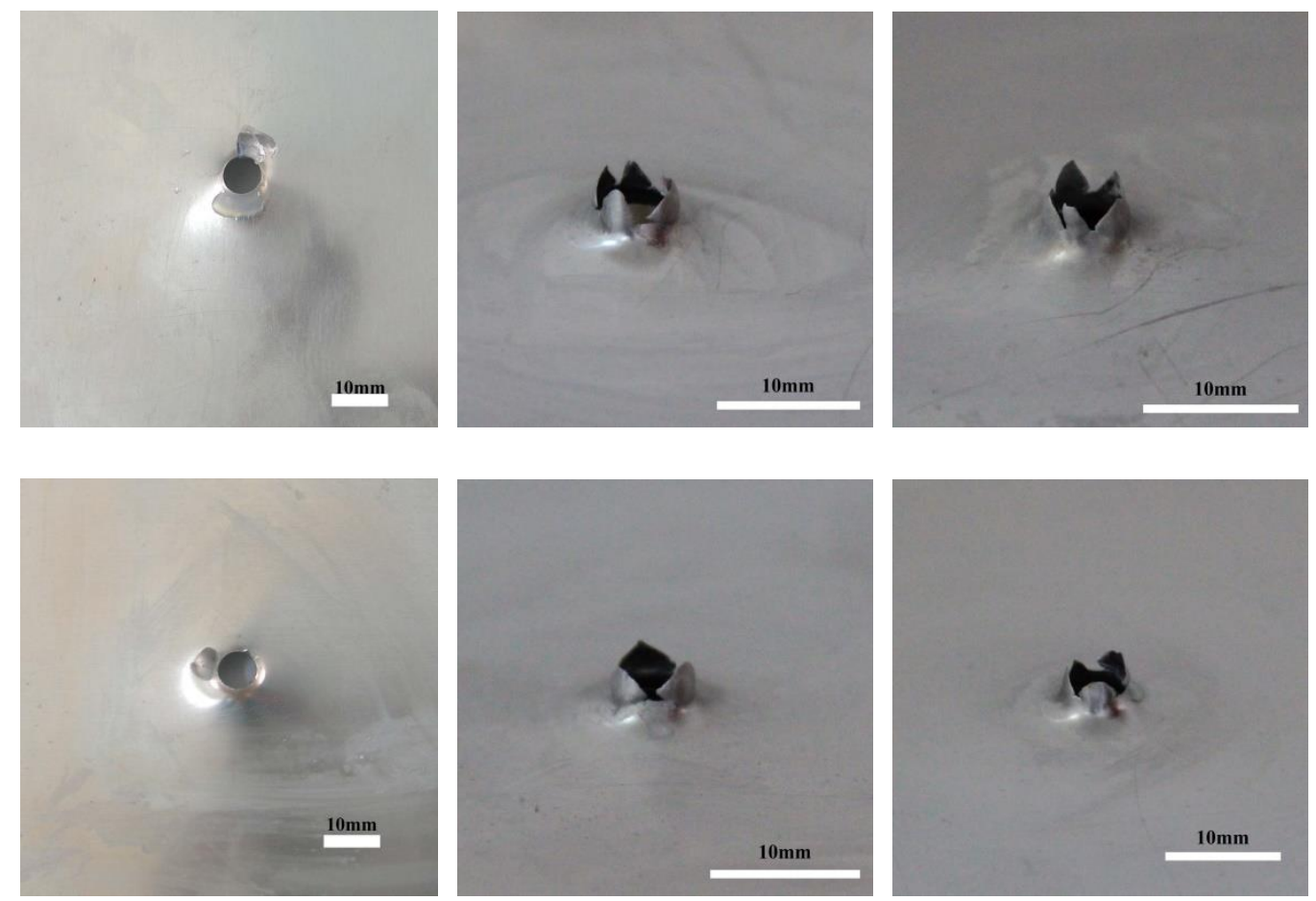

Fig. 5 Typical failure modes of the asymmetrical sandwich plate: (a) with 54\% STFs at $70.67 \mathrm{~m} / \mathrm{s}(\mathrm{A}-54-2)$; (b) with $54 \%$ STFs at $93.44 \mathrm{~m} / \mathrm{s}(\mathrm{A}-54-3)$; (c) with $54 \%$ STFs at $113.83 \mathrm{~m} / \mathrm{s}(\mathrm{A}-54-4)$; (d) with $56 \%$ STFs at $80.1 \mathrm{~m} / \mathrm{s}(\mathrm{A}-54-2)$; (e) with $56 \%$ STFs at $93.15 \mathrm{~m} / \mathrm{s}(\mathrm{A}-54-2)$ and (f) with $56 \%$ STFs at $105.8 \mathrm{~m} / \mathrm{s}(\mathrm{A}-54-2)$.

\subsection{Deformation mechanism}

According to the failure modes of the rear sheets and the residual velocity of the projectile, the failure mechanisms of different load cases are as follows.
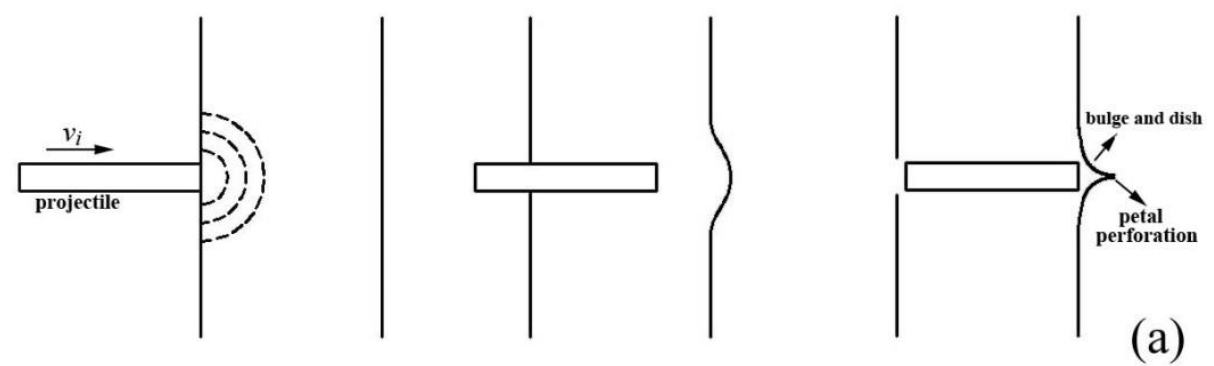

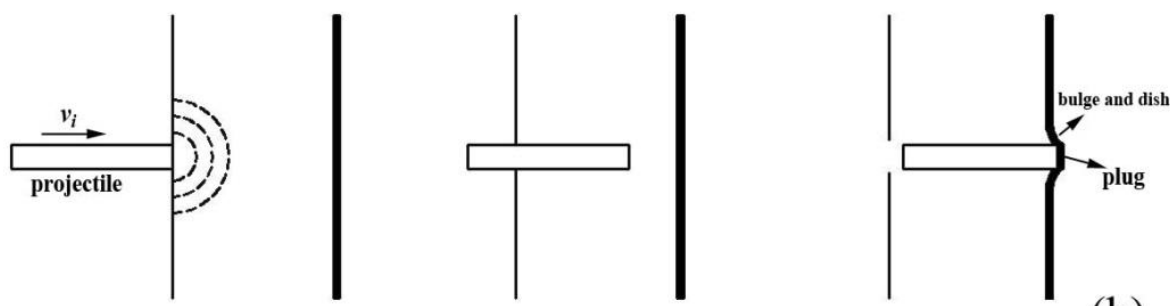

(b)

Fig. 6 Schematic diagram of the penetration of sandwich plates with: (a) thin rear sheet and (b) thick rear sheet.

During penetration, if the projectile impacts directly onto the face sheet, the stress caused by the impact can be evaluated by $\sigma=\frac{\left(\rho_{1} \mathrm{c}_{1}\right)\left(\rho_{2} \mathrm{c}_{2}\right)}{\rho_{1} \mathrm{c}_{1}+\rho_{2} \mathrm{c}_{2}} v$, where $\sigma$ is the impact stress, $\rho$ is the density, $c$ is the stress wave velocity and $v$ is the impact velocity. If the impact velocity is $40 \mathrm{~m} / \mathrm{s}$, the impact stress would be approximately $404 \mathrm{MPa}$, which far exceeds the strength of pure aluminium and results in plug failure [23-24].

In the present paper, when the impact velocity is less than $80 \mathrm{~m} / \mathrm{s}$, the projectile penetrates the front face sheet in plug mode, and then continues to move through the core of the STFs, which increases the viscosity (even into solid-like state) around the projectile. The projectile was decelerated by the STFs with high viscosity, which also creates a squeeze stress in the front of the projectile. The projectile pushes the STFs with high viscosity to move ahead and act on the rear face sheet, which can be considered as a concentrated load exerted on rear face sheet. If the rear face sheet is $0.2 \mathrm{~mm}$ thick, it is easily deformed into a dish with tensile stress in the radial and circumferential directions [25], and then develops into petal failure mode, as shown in Fig. 6 (a). If the rear face sheet is $0.5 \mathrm{~mm}$ thick, it is harder to deform. So, the 
projectile would penetrate the core of the STFs and act directly on the rear sheet causing plug failure mode, as shown in Fig. 6 (b).

When the impact velocity is more than $90 \mathrm{~m} / \mathrm{s}$, the impact stress increases proportionally. The failure mechanism of the symmetrical sandwich plate (the rear sheet is $0.2 \mathrm{~mm}$ thick) is similar to that described above, as shown in Fig. 6 (a). The failure mechanism of the asymmetrical sandwich plate at the velocity larger than 90 $\mathrm{m} / \mathrm{s}$ is different from that at the velocity less than $80 \mathrm{~m} / \mathrm{s}$. Though the $0.5 \mathrm{~mm}$ thick rear sheet is harder to deform than the $0.2 \mathrm{~mm}$ thick sheet, as the projectile moves through the STFs with high velocity, it also produces high internal stress that results in a dish deformation in the $0.5 \mathrm{~mm}$ thick rear face sheet, and then develops to the petal failure mode like that occurs in $0.2 \mathrm{~mm}$ thick rear face sheet.

\subsection{Residual velocity and energy absorption}

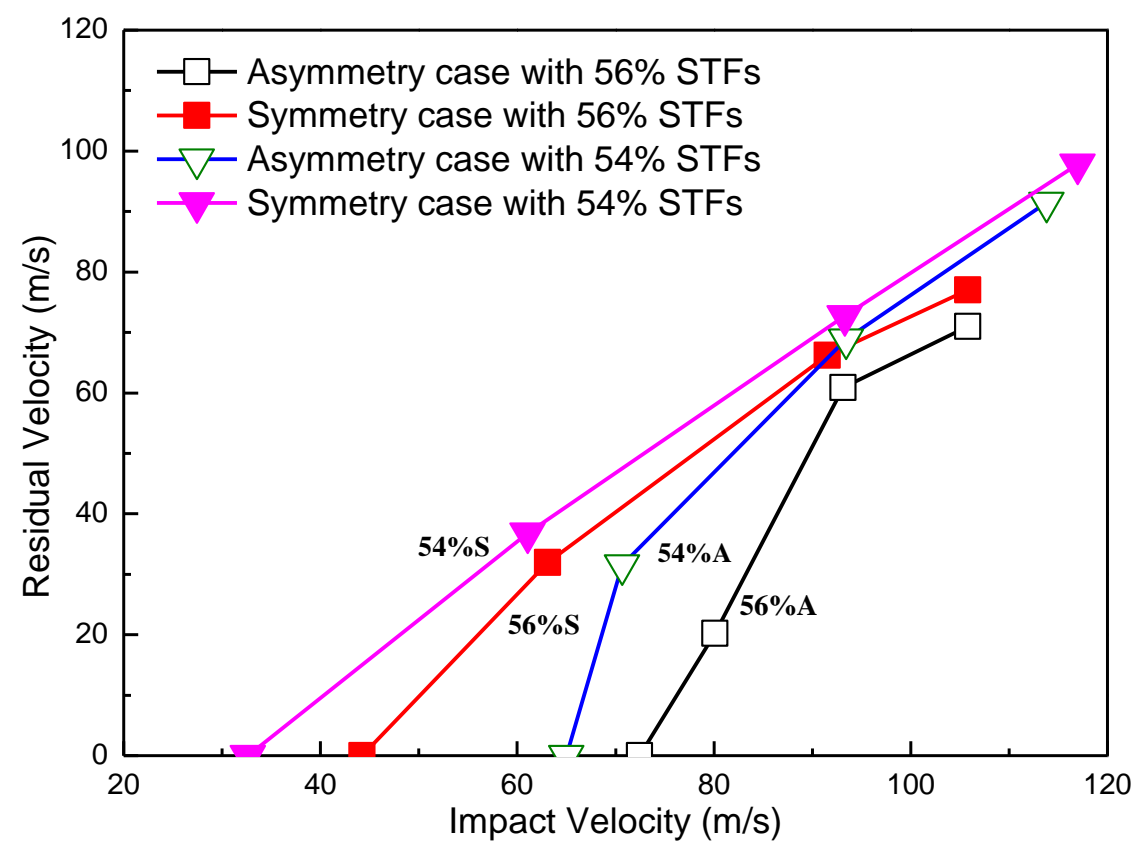

Fig. 7 The curves of residual velocity of the projectile at different impact velocities. 
Figure 7 shows the residual velocity of the projectile at different impact velocities. There is an obvious difference in the residual velocity in that the residual velocity of the symmetrical case is less than that of the asymmetrical case at low impact velocity, which is due to the thickness of the rear face sheet; but this difference decreases with the increasing of the impact velocity. We considered there are two reasons: (1) the impact stress increased promptly with the impact velocity, which reduced the influence of the thickness of the rear sheet; (2) the shear stress acted on the projectile by the STFs increased with the velocity due to the shear thickening effect.

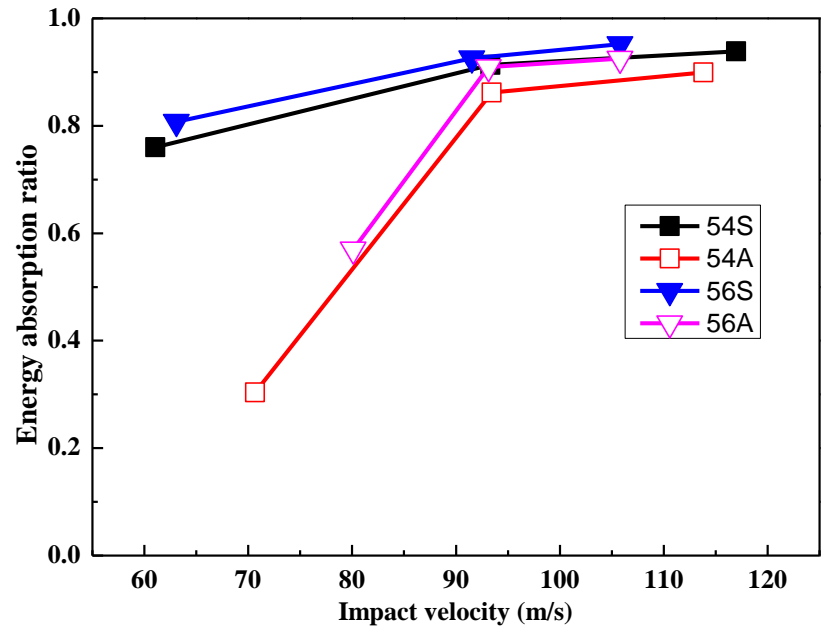

Fig. 8 The curves of the energy absorption ratio of STFs to initial kinetic energy.

Energy absorption percent by STF core was defined as follows:

$$
\eta=\frac{E_{i n}-E_{r}-E_{0}}{E_{\text {in }}}
$$

where $\eta$ is the relative energy absorption efficiency, $E_{i n}$ and $E_{r}$ are the initial energy and residual energy of the projectile, respectively, $E_{i n}-E_{r}$ is the energy absorbed by the sandwich plate with an STFs core, and $E_{0}$ is the energy absorbed by the sandwich plate without core. 


$$
E_{i n}=\frac{1}{2} m v_{i n}^{2}, \quad E_{r}=\frac{1}{2} m v_{r}^{2}, E_{0}=\frac{1}{2} m v_{i n 0}^{2}-\frac{1}{2} m v_{r 0}^{2}
$$

where $v_{i n}$ and $v_{r}$ are the impact velocity and residual velocity for the case of sandwich plate with STFs core, $v_{i n 0}$ and $v_{r 0}$ are the impact velocity and residual velocity for the case of sandwich plate without core, and $\mathrm{m}$ is the mass of the projectile.

Fig. 8 illustrates that the energy absorption ratio of symmetrical case is larger than that of asymmetrical case at the low impact velocity, but the difference in the energy absorption ratio between the symmetrical and asymmetrical cases decreases as the impact velocities increase. We explained the reasons as follows.

At the low impact velocity, the impact stress is also low, which cannot result in a fast petal/plug failure, so the thick face sheet would deform before petal/plug failure occurs. Moreover, the thick face sheet can absorb more energy as it deforms, so the energy absorption ratio of asymmetrical case is small at the low impact velocity.

The impact stress increases quickly as the impact velocity increases; this means a high impact stress causes the thick/thin face sheets to fail in petal/plug quickly and experience almost no deformation. Moreover, the face sheets absorb almost no energy. It means that most of the energy was absorbed by STF core in the all load cases. This is in agreement with that the difference in the energy absorption ratio in different load cases is small at high impact velocities in Fig. 8.

\section{Conclusions}

The failure mechanism and energy absorption of the sandwich plate with an STF core subjected to the impact of a projectile was studied in this paper. The failure 
modes of symmetrical and asymmetrical constructed sandwich plates were different at low impact velocities due to the thickness of the rear sheet, and then both two types of sandwich structures failed in petal torn mode at high impact velocity.

The energy absorbed by the sandwich plate with STFs core increased with the increasing of the impact velocity, while the energy absorption of 56\% STFs was more than that of $54 \%$ STFs at different impact velocities, but the difference between the energy absorbed by the 54\% and 56\% STFs decreased as the impact velocity increased.

\section{Acknowledgements}

This work was supported by the National Natural Science Foundation of China (No. 11202071) and the Fundamental Research Funds for the Central Universities, Wuhan University of Technology (WUT: 2015-III -026).

\section{References}

[1] Kolopp A, Rivallant S, Christophe Bouvet, Experimental study of sandwich structures as armour against medium-velocity impacts, Int J Impact Eng, 2013, 61: 24-35.

[2] Wang Q, Chen Z, Chen Z, Design and characteristics of hybrid composite armor subjected to projectile impact, Mater Design, 2013, 46(4): 634-639.

[3] Reddy BG, Sharma KV, Reddy T, Deformation and impact energy absorption of cellular sandwich panels, Mater Design, 2014, 61(9): 217-227.

[4] Dean J, S-Fallah, A, Brown PM, Louca LA, Clyne TW, Energy absorption during 
projectile perforation of lightweight sandwich panels with metallic fibre cores, Compos Struct, 2011, 93(3): 1089-1095.

[5] Wagner N, Brady J, Shear thickening in colloidal dispersions, Phys Today, 2009, 62(10):27-32.

[6] Ding J, Tian T, Meng Q, Guo Z, Li W, Zhang P, et al., Smart Multifunctional Fluids for Lithium Ion Batteries: Enhanced Rate Performance and Intrinsic Mechanical protection, Sci Rep, 2013, 3(2485): 1-7.

[7] Maranzano J. B, Wagner J. N, The effects of particle size on reversible shear thickening of concentrated colloidal dispersions, J Chem Phys, 2001, 114(23): 10514-27.

[8] Jiang W, Ye F, He Q, Gong X, Feng J, Lu L, Xuan S, Study of the particles' structure dependent rheological behavior for polymer nanospheres based shear thickening fluid, Journal of Colloid and Interface Science, J Colloid Interface Sci, 2014, 413: 8-16.

[9] Jiang W, Gong X, Xuan S, Jiang W, Ye F, Li X, Liu T, Stress pulse attenuation in shear thickening fluid, Appl Phys Lett, 2013, 102(101901):1-5.

[10]Lim A, Lopatnikov S, Wagner N, Gillespie Jr. J, Investigating the transient response of a shear thickening fluid using the split Hopkinson pressure bar technique, Rheol Acta, 2010, 49: 879-890.

[11]Petel O, Ouellet S, Loiseau J, Frost D, Higgins J. A, A comparison of the ballistic performance of shear thickening fluids based on particle strength and volume fraction, Int J Impact Eng, 2015, 85: 83-96. 
[12]Galindo-Rosales FJ, Rubio-Hernandez FJ, Sevilla A, An apparent viscosity function for shear thickening fluids, An apparent viscosity function for shear thickening fluids, J Non-Newton Fluid Mech, 2011,166:321-325.

[13]Lu Z, Jing X, Sun B, Gu B, Compressive behaviors of warp-knitted spacer fabrics impregnated with shear thickening fluid, Compos Sci Technol, 2013, 88:184-189.

[14]Majumdar A, Butola BS, Srivastava A, Development of soft composite materials with improved impact resistance using Kevlar fabric and nano-silica based shear thickening fluid, Mater Design, 2014, 54:295-300.

[15]Reis PNB, Ferreira JAM, Santos P, Richardson MOW, Santos JB, Impact response of Kevlar composites with filled epoxy matrix, Compos Struct, 2012, 94: $3520-3528$.

[16] Srivastava A, Majumdar A, Butola BS, Improving the impact resistance performance of Kevlar fabrics using silica based shear thickening fluid, Mater Sci Eng A, 2011, 529: 224- 229.

[17] Rabb R, Fahrenthold E, Evaluation of shear-thickening-fluid Kevlar for large-fragment-containment application, J Aircraft, 2011, 48(1): 230-234.

[18]Feng X, Li S, Wang Y, Wang Y, Liu J, Effects of different silica particles on quasi-static stab resistant properties of fabrics impregnated with shear thickening fluids, Mater Design, 2014, 64: 456-461.

[19]Park Y, Kim Y, Baluch AH., Kim C, Empirical study of the high velocity impact energy absorption characteristics of shear thickening fluid (STF) impregnated Kevlar, Int J Impact Eng, 2014, 72: 67-74. 
[20] Fischer C, Braun SA, Bourban PE, Michaud V, Plummer CJG, Manson JAE, Dynamic properties of sandwich structures with integrated shear-thickening fluids, Smart Mater Struct, 2006, 15:1467-1475.

[21]Branda F, Silvestri B, Luciani G, Costantini A, The effect of mixing alkoxides on the Stober particles size, Colloid Surface A, 2007, 299(1-3): 252-255.

[22] Stober W, Fink A, Bohn E, Controlled growth of monodisperse silica spheres in the micron size range, J Colloid Interface Sci, 1968, 26(1): 62-69.

[23]Kimura M, Fuji A, Shibata S, Joint properties of friction welded joint between pure magnesium and pure aluminium with post-weld heat treatment, Mater Design, 2015, 85 (11): 169-179.

[24]Iqbal MA, Tiwari G, Gupta PK, Bhargava P, Ballistic performance and energy absorption characteristics of thin aluminium plates, In J Impact Eng, 2015, 77: $1-15$.

[25]Backman M, Goldsmith W, The mechanics of penetration of projectiles into targets, Int J Eng Sci, 1978, 16:1-99. 
Figure Captions

Fig. 1 The SEM graph of the $\mathrm{SiO}_{2}$ particle.

Fig. 2 Schematic diagram of the experimental configuration.

Fig. 3 The curves of viscosity vs. shear strain rates of $54 \%$ and $56 \%$ STFs.

Fig. 4 Typical failure modes of symmetrical sandwich plate: (a) without STF core at $115.6 \mathrm{~m} / \mathrm{s}(\mathrm{S}-0-2)$, (b) with $54 \%$ STFs at $61.07 \mathrm{~m} / \mathrm{s}(\mathrm{S}-54-2)$ and (c) with $56 \%$ STFs at $105.8 \mathrm{~m} / \mathrm{s}(\mathrm{S}-56-4)$.

Fig. 5 Typical failure modes of the asymmetrical sandwich plate: (a) with 54\% STFs at $70.67 \mathrm{~m} / \mathrm{s}(\mathrm{A}-54-2)$; (b) with $54 \%$ STFs at $93.44 \mathrm{~m} / \mathrm{s}(\mathrm{A}-54-3)$; (c) with $54 \%$ STFs at $113.83 \mathrm{~m} / \mathrm{s}(\mathrm{A}-54-4) ;(\mathrm{d})$ with $56 \%$ STFs at $80.1 \mathrm{~m} / \mathrm{s}(\mathrm{A}-54-2)$; (e) with $56 \%$ STFs at $93.15 \mathrm{~m} / \mathrm{s}(\mathrm{A}-54-2)$ and (f) with $56 \%$ STFs at $105.8 \mathrm{~m} / \mathrm{s}(\mathrm{A}-54-2)$.

Fig. 6 Schematic diagram of the penetration of sandwich plates with: (a) thin rear sheet and (b) thick rear sheet.

Fig. 7 The curves of residual velocity of the projectile at different impact velocities.

Fig. 8 The curves of the energy absorption ratio of STFs to initial kinetic energy.

Table Captions

Table 1 The experimental results. 